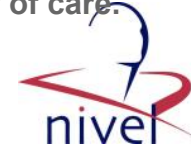

\begin{tabular}{|l|l|}
\hline $\begin{array}{l}\text { Postprint } \\
\text { Version }\end{array}$ & 1.0 \\
\hline Journal website & $\underline{\text { http://www.jahonline.org/article/S1054-139X(14)00256-0/fulltext }}$ \\
\hline Pubmed link & $\underline{\text { https://www.ncbi.nlm.nih.gov/pubmed/25149686 }}$ \\
\hline DOI & 10.1016/j.jadohealth.2014.06.008 \\
\hline
\end{tabular}

This is a NIVEL certified Post Print, more info at http://www.nivel.eu

\title{
Young Adults' Experiences and Satisfaction With the Transfer of Care
}

\author{
AnneLoesvan StaaR.N., M.D., M.A., Ph.D. ${ }^{A B} J$ Ane N.T.SattoeM.SC. ${ }^{A B C}$ \\ ${ }^{a}$ Research Center Innovations in Care, Rotterdam University of Applied Sciences, \\ Rotterdam, The Netherlands \\ ${ }^{\mathrm{b}}$ Institute of Health Policy and Management, Erasmus University Rotterdam, Rotterdam, The \\ Netherlands \\ ' Sophia Children's Hospital, Erasmus University Medical Center Rotterdam, Department of \\ Pediatrics, Rotterdam, The Netherlands
}

\begin{abstract}
Purpose

Transition of care of adolescents with chronic conditions is a critical area for clinicians. Patient-reported outcomes may provide important information on the quality of services. This cohort study examines young adults' experiences and satisfaction with the transfer to adult care and explores associations with patient characteristics.

Methods

Follow-up of 518 young adults (18-25 years) with various chronic conditions who completed a Web-based survey in 2006 (response rate, 52\%). Outcome measures were the 18-item On Your Own Feet Transfer Experiences Scale $(\alpha=$ .93) and satisfaction with the transfer process (visual analog scale). Associations with demographic and health care-related variables, health-related quality of life, and self-management were explored with stepwise multivariate modeling, using past (2006-T0) and current (2012-T1) variables.

Results

Of the respondents, $315(65 \%)$ had transferred, while $10 \%$ was still in pediatric care and $25 \%$ was not in treatment anymore. Twenty percent rated their transfer as unsatisfactory, $50 \%$ felt prepared at the time of transfer, and $24 \%$ had met their adult-centered provider in advance. Men were more positive about their experiences and rated satisfaction higher than did women. Patient-centeredness of the adult health-care provider was the most important determinant for experiences $(\beta=.29)$. Higher self-efficacy at $\mathrm{T} 1$ was associated with more positive experiences but not with higher satisfaction. The latter was higher for those transferred within the same hospital $(\beta=.28)$.

Conclusions
\end{abstract}


The On Your Own Feet Transfer Experiences Scale is a useful instrument to measure transfer experiences. The importance young adults attach to good relations with their new provider stresses the necessity of early involvement of and good collaboration with adult care.

\section{IMPLICATIONS AND CONTRIBUTION}

Transition of care is a critical area for adolescent health. This longitudinal study reported mixed experiences and satisfaction of young adults with moving to adultcentered care. Patient centeredness of the provider was most strongly associated with positive experiences indicating the importance of making adult services more responsive to young adults' needs.

The past decades have seen a surge of interest in the challenges that young people with chronic conditions and special health care needs face when progressing into adulthood. The transition from child-centered to adult-oriented health care systems is part of a longer life-course transition for adolescents with chronic conditions-a critical area for future health status and degree of social participation [1]. Since Blum et al. defined transition as a multifaceted process in 1993 [2], dozens of journal articles and editorials have called for a better preparation of all parties involved and for a seamless and safe transition process [3]. Unfortunately, there has been a slow uptake of recommendations made [4-6]. A recent national U.S. survey showed that the support needed for successful transition to adult care (AC) is mostly wanting [7]. Studies from different countries and in different diagnostic groups have consistently pointed out the lack of planning, communication, and coordination surrounding the transfer of care. Recent reviews have also pointed out the paucity of evidence to inform the best practice about both the process of and what constitutes effective transitional care programs [8-11] and the absence of longitudinal research into adult outcomes [9].

Moreover, young people's voices are often overlooked, although they consistently ask to be involved in the process and want providers to listen to them and be sensitive to their needs $[10,12,13]$. A qualitative metasynthesis of 18 studies of adolescents' and young adults' (YA's) experiences with the transition from pediatric to adult hospital care found comparable experiences across diagnoses. Feelings of not belonging, being redundant, and being unprepared during the transfer process were strikingly frequent [14]. Young people's experiences can be summarized into four major themes: facing changes in significant relationships, moving from a familiar to an unknown setting and culture, being prepared for transfer, and achieving responsibility [14]. Our previous qualitative study found that transition experiences and views of young people overlapped with those of their parents and professionals [13]. Leaving pediatric care (PC) was seen as a "logical step," and participants noted specific positive and negative aspects of both settings. However, all desired better preparation, more collaboration, and personal links between pediatric and adult providers $[10,14]$. As an important patient-reported outcome measure for the quality of the transition process, YA's experiences and satisfaction with this process should be collected systematically, along with other relevant outcomes such as health status, quality of 
life, social participation, self-management skills, access to and quality of AC $[8,15]$. There are very few reliable and valid measures that assess these outcomes [15]. A recent review of transfer satisfaction measures identified only seven studies [16]. Although some studies reported negative experiences [17] and significant worries [18], in another study, participants had no concerns and were satisfied [19]. Most studies were descriptive and used small disease-specific samples with cross-sectional designs. Measures were usually developed ad hoc without following the established guidelines for patient reported outcomes [20]. Also, different concepts were measured at the same time (e.g., concern, attitudes, satisfaction), and all measures had poor quality according to the COSMIN checklist criteria [16,20]. COSMIN stands for COnsensus-based Standards for the selection of health Measurement Instruments. The checklist can be used to determine whether a study on measurement properties meets the standards for good methodological quality [20]. Only one instrument ("Mind The Gap" [21]) has established reliability and validity, but it is not developed for measuring post-transfer experiences. Thus, there are no validated instruments to explore experiences during the transition from PC to AC.

Longitudinal studies exploring YA's self-reported outcomes during transition are rare [10,22,23], and factors exerting a positive influence on adult outcomes are still unknown. In this study, a large sample of adolescents with various chronic conditions was followed into young adulthood. The aim of the study was to examine post-transfer experiences and satisfaction with transfer and to link these with patient characteristics in adolescence and young adulthood.

\section{METHODS}

\section{Participants and study design}

The respondents of a Web-based questionnaire in 2006 (T0; $n=1,039)$ [24] were invited for a similar survey in 2012 (T1). In 2006, they were adolescents between 12 and 18 years of age, who had been undergoing treatment in the Erasmus Medical Centre (MC) - Sophia's Children's Hospital Rotterdam for more than 3 years. The original sample presented with a broad range of chronic somatic conditions without intellectual disabilities. In 2012, current provider, health-care utilization, recent contact addresses, and death notices were retrieved for the hospital's electronic patient records. Eligible YA were sent information and a unique password to $\log$ in on a secured Web site. Those who did not respond within a month were sent a reminder by post. After another month, nonresponders were approached by phone. Respondents were entered in a lottery to win one of twenty-five cookbooks, two smart phones, or an iPad.

\section{Ethical concerns}

The study was approved by the Medical Ethics Committee of the Erasmus MC, and all data were processed anonymously. Participants provided assent for their participation in the study.

\section{Variables}

The new Web-based questionnaire was partly based on the previous instrument [24] and was pilot tested in seven face-to-face and three telephone interviews with young university students with chronic conditions, who were not included in the final sample. 


\section{Outcome measures}

Two new measures to assess experiences with transfer from PC to AC were developed. The first was the newly constructed On Your Own Feet Transfer Experiences Scale (OYOF-TES) based on our previous qualitative research [13] and a review of existing measures. It was critically reviewed by nurses and pediatricians and then pilot tested with YA in different settings. The items focus on experiences with the transfer process because satisfaction scores often present a limited and optimistic picture. Questions about specific experiences seem more useful because these can point to ways in which delivery of care can be improved [25]. The OYOF-TES consists of 18 items rated on five-point Likert scales $(1=$ strongly disagree to $5=$ strongly agree). Exploratory factor analysis, followed by confirmatory factor analysis with Oblimin rotation resulted in two domains: (1) perceived alignment and collaboration between PC and AC (11 items, Cronbach alpha $(\alpha)=.91$ ) and (2) experienced preparation for transfer including readiness, timing, and co-decision making (seven items, $\alpha=.89$ ). Correlation between the subscales was $r=.56$. A total of $57.3 \%$ of the variance was explained. Supplementary Appendix 1 presents the means and scores of the OYOF-TES items and their factor loadings on the subscales.

The second outcome measure concerned satisfaction with the transfer process, using a visual analog scale by asking the YA "How satisfied are you with the overall process of your transfer to adult care on a scale ranging from 1 to 10?"

\section{Independent variables}

\section{Demographic variables}

Age and gender were recorded in both years, while data from the T0 questionnaire served to establish physical limitations in mobility $(0=$ no; $1=$ yes $)$ and age at onset of the chronic condition (before vs. after the age of 5 years) [24]. At T1, the present level of education $(1=$ low [prevocational education or secondary vocational education; level 1-3]; 2 = medium [prevocational education or secondary vocational education; level 4]; $3=$ high [preuniversity and/or senior general secondary education or higher educational institutions]) and type of education followed in the past $(1=$ mainstream; 2 = special education $)$ were assessed. Respondents were asked whether they were recipients of disability benefits under the Dutch Income Provision Act for Disabled Young People.

\section{Health care-related variables}

Health care-related variables were computed from the electronic patient records at T1. These included age at transfer and timing of the transfer, taken as the number of years since the last consultation in PC. In Table 1, this continuous variable was recoded to reflect how long ago transfer had taken place $(0=$ in the past 2 years, $1=$ 3-4 years ago, $2=5-6$ years ago). The variable adult health care setting indicates whether transfer was within Erasmus MC or to another hospital. For those still treated in Erasmus MC, the number of consultations and of hospitalizations and the number of missed appointments in the past 3 years were also computed. 
Staa, A. van, Sattoe, J.N.T. Young adults' experiences and satisfaction with the transfer of careJournal of Adolescent Health: 2014, 55(6), 796-803

\section{[TABLE 1]}

\section{Self-management}

Self-management was operationalized through various self-reported measurements. Disease-related self-efficacy was measured at T0 and T1 with the On Your Own Feet Self-Efficacy Scale (OYOF-SES) using a four-point Likert scale (from 1 = "no, definitely not" to $4=$ "yes certainly") [24]. It consists of 17 items assigned to knowledge, coping, and skills for hospital consultations. One item ("I know what will happen to me when I transfer to adult care") was deleted, because it did not apply to those already transferred at T1. Hence, 16 items were offered $(\alpha=.87)$. General score of independence during consultations was self-reported on a visual analog scale (range, 1-10). Independent behavior during consultations was self-reported at T0 with a dichotomous seven-item scale $(\alpha=.55)$. To improve internal consistency, a five-point Likert scale was used at T1 $(\alpha=.79)$ (from $1=$ "never" to $5=$ "always").

\section{Attitude toward care and transition}

Attitude toward care and transition was measured at T0 in different ways. The Attitude toward transition scale consisted of four quotes from adolescents. Responses were scored on a five-point Likert scale from $1=$ "totally disagree" to $5=$ "totally agree" $(\alpha=.74)$ [13]. Adolescents also stated on a five-point Likert scale how often transition of care was being discussed during consultations and how important they considered it to be [24]. Transfer readiness was assessed by a single question: "Do you think that you are ready to transfer to adult care?" (from 1 = "no, definitely not" to 4 = "yes, definitely") [24]. Patient centeredness of the current health-care provider was only measured at $\mathrm{T} 1$ with a five-item four-point Likert scale (from $1=$ "never" to $4=$ "always"; $\alpha=.90$ ). The scale is a validated Dutch adaptation of one scale from the American Consumer Assessment of Health Plan Surveys questionnaire [26].

\section{Health-related quality of life}

Health-related quality of life $(H R Q O L)$ was assessed at T0 and T1 using the selfreport short-form measure of the DISABKIDS questionnaire [27] (DCGM-10; T0 $\alpha=.78 ; \mathrm{T} 1 \alpha=.90)$; scores are transformed to a $0-100$ scale.

\section{Data analysis}

Backward logistic analysis was used to detect selective response; determinants of study nonresponse were expressed in odds ratios (ORs) with $95 \%$ confidence intervals (CI), and Nagelkerke $R^{2}$ indicated the proportion of explained variance. Model fit was tested with the Hosmer and Lemeshow test. Descriptive statistics were used to describe the study sample. Bivariate correlations (Pearson's $r$ or Spearman's $\rho$ ) between the outcome and other variables were established to determine which variables should be included in the regression analyses. Stepwise multivariate linear regression analyses were performed to identify factors associated with transfer experiences (TE) and transfer satisfaction (TS): starting with background variables and then adding T0 and subsequently T1 variables. For HRQoL and self-efficacy at T1, change scores $(\Delta)$ were used. Only variables significantly correlated $(p<.05)$ with (one of) the outcome variables were included in the regression models. Multicollinearity was checked by calculating the variance inflation factor. 
Staa, A. van, Sattoe, J.N.T. Young adults' experiences and satisfaction with the transfer of careJournal of Adolescent Health: 2014, 55(6), 796-803

\section{RESULTS}

\section{Follow-up after 6 years: total sample}

Of the 1,039 participants in the original study, 13 (1.25\%) had died and 25 could not be traced. Consequently, 1,001 YA were included in the total study sample (Figure 1). Mean age was 20.59 years (standard deviation [SD], \pm 1.90 ; range, 18 25 years) and 447 (44.7\%) were male. According to the hospital's electronic patient records, $593(59.3 \%)$ had been transferred to AC $(n=466$ within the same university hospital and $n=127$ to other hospitals), whereas 139 (13.9\%) were still treated in PC. For 268 patients $(26.8 \%)$, information about their current health-care provider was unknown. Only in one record was it clearly stated that the patient had been officially discharged and transferred to primary care.

\section{[FIGURE 1]}

For those YA who were still treated in the same university hospital $(n=605)$, data on health-care utilization in the past 3 years could be retrieved. YA treated in PC were younger than those transferred to $\mathrm{AC}(p<.001)$, whereas no-show for scheduled appointments was greater in the group transferred to $\mathrm{AC}(p<.01)$; the mean number of missed consultations in the past 3 years being $.78(\mathrm{SD} \pm 1.86)$ in AC versus .36 $(\mathrm{SD} \pm .92)$ in $\mathrm{PC}$.

\section{Response and final study sample}

Of the 1,001 invited, 606 YA responded (60.5\%); 88 of whom returned a postcard stating they declined from participation (14.5\%). Eventually, 518 YA (aged 1825 years) submitted the survey (net response rate, 51.8\%). Nonresponse was associated with male gender (OR, .57; 95\% CI, .43-.74), and non-Dutch ethnicity $\left(\mathrm{OR}, .49 ; 95 \% \mathrm{CI}, .33-.74 ; \chi^{2}=29.0, \mathrm{df}=2 ; p<.001 ; R^{2}=.04\right.$; Hosmer and Lemeshow test $p=.77$ ). Compared with the responders, the nonresponders more often belonged to the group for which no current health-care provider had been indicated in the hospital's electronic patient records $(p<.01)$.

Thirty respondents did not mention their current health-care provision. Of the remaining 488, 48 (9.8\%) were still in PC and 125 (25.6\%) were not in active treatment anymore. Ultimately, $315(64.6 \%)$ had transferred to AC and could be included in the analyses. Forty percent had transferred in the past 2 years, 30.6\% 34 years ago, and 29.6\% 5-6 years. Seventy-five percent of these $(n=236)$ remained in Erasmus MC. Mean age at transfer was 17.6 years $(\mathrm{SD}=1.83) ; 55.5 \%$ transferred at 17 or 18 years of age. Characteristics are summarized in Table 1.

\section{Experiences and satisfaction with transfer}

Self-efficacy and independence during consultation had increased between $\mathrm{T} 0$ and T1 (both $p<.001$ ), whereas HRQoL had decreased $(p=.001)$.

The mean of the OYOF-TES was 61.83 (SD = 13.22; range, 18-90). The scale was normally distributed (skewness $=-.47 ; \mathrm{SE}=.14$ ). The most appreciated items were "I have confidence in my adult healthcare providers" (80.9\% agreed), "I can manage well on my own during hospital consultations, also without my parents" (78.7\% agreed), and "The transfer to adult care was announced timely and did not come as a surprise" (77.2\% agreed). The least appreciated items were "Before the transfer I had already met my new healthcare providers" (23.5\% agreed); "When I first met my adult care provider, I knew exactly what was expected of me and what I could expect from him/her" (38.1\% agreed); and "I had a say in the timing of the 
transfer" (39.7\% agreed). Almost half (49.2\%) felt they had been well prepared and $43.8 \%$ stated they received enough information. Supplementary Appendix 1 lists all OYOF-TES items and means.

Mean TS was 6.63 (range, $1-10 ; \mathrm{SD}=1.79 ; 95 \% \mathrm{CI}, 6.52-6.85$ ); the median was 7 (interquartile range $=2$ ). One-fifth $(19.4 \%)$ scored their transfer process below six (i.e., unsatisfactory), whereas $34.4 \%$ was very satisfied (score $\geq 8$; Figure 2 ). YA who remained in Erasmus MC were more satisfied with the overall transfer process than those transferred to other hospitals $(p<.01)$, whereas OYOF-TES scores and ratings of patient centeredness of the current provider did not significantly differ between these groups. The total OYOF-TES was highly correlated with TS $(r=.75 ; p<.001)$. The correlation between TS and the OYOF-TES subscale A (alignment) was greater $(\mathrm{r}=.73 ; p<.001)$ than with subscale B (preparation; $r=.62 ; p<.001)$. The two OYOF-TES items that correlated best with satisfaction were "I was taken care of very well in the adult care setting" and "There was good collaboration between pediatric and adult care" $(r=.64)$.

\section{[FIGURE 2]}

\section{Associations with transfer experiences and satisfaction}

To determine which variables should be included in the regression analyses, bivariate correlations were tested (Table 2). The OYOF-TES multivariate model explained $30 \%$ of the total variance; for TS, this was $21 \%$ (Table 3). Variance inflation factor scores varied between 1 and 2; indicating the absence of multicollinearity.

\section{[TABLE 2][TABLE 3]}

Men were more positive about their TE $(\beta=.17 ; p<.001)$ and scored their TS greater than women $(\beta=.12 ; p=.03)$. Patient centeredness of the adult health-care provider was the most important determinant for TE $(\beta=.29 ; p<.001)$ and was also strongly correlated with TS $(\beta=.16 ; p<.004)$. Attitude toward transition at T0 $(\beta=$ $15 ; p=.005)$ and greater self-efficacy change at $\mathrm{T} 1(\beta=.16 ; p=.05)$ were positively associated with TE, but not with TS. Satisfaction was greater when YA remained in Erasmus MC $(\beta=.28 ; p \leq .001)$ and when YA thought discussing the transition was important at $\mathrm{T} 0(\beta=.11 ; p=.04)$.

\section{Discussion}

After 6 years of follow-up, about $60 \%$ of the original sample had transferred to AC, $13.9 \%$ were still seen in PC, while in a quarter their destination was unknown. YA's satisfaction with transfer to AC was not general: about one-third was very satisfied, but one-fifth rated their transfer as unsatisfactory. Men were more positive than women, mirroring the fact that boys reported higher readiness before transfer [24]. One other study found that girls anticipated more difficulties than boys [28]. More positive experiences were also predicted by attitude toward transition at baseline, confirming the importance of attitudes and expectations in transition $[23,29,30]$. No other baseline variables predicted TE or TS.

The main determinant of reporting positive TE was the degree of patient centeredness of the adult-oriented provider. Receiving a warm welcome in AC and experiencing good alignment and collaboration between pediatric and adult services seem crucial factors for a positive experience. The importance of provider 
characteristics in adolescent care is well known [31], but its relevance for young AC has not been reported before. Concerns about transition mainly originate from PC, and few studies have included adult providers [32,33]. As a consequence, today's debate focuses on better preparation of adolescents, including (measuring) transition readiness $[16,34,35]$, whereas making adult services more responsive to YA's needs receives less attention [36].

Transitional care should not be confined to a pediatric paradigm and be disconnected from the principles and practice of adolescent medicine [37]. The transition process continues into young adulthood and therefore AC. Still, different studies have indicated that up to $25 \%$ of YA became disconnected with care in the first year after transfer $[19,38]$. In our study, a quarter of the total sample did not receive follow-up in $\mathrm{AC}$ anymore, but reasons for this are not known. Promoting continuity of contact could reduce the risk of long-term disengagement with care [38]. In our total sample, the percentage of missed clinic appointments was greater in those treated in $\mathrm{AC}$ compared with PC, indicating a risk of disengagement.

Our sample had faith in their adult providers and was happy with the care received. Yet, less than half felt sufficiently prepared, confirming findings from other studies $[19,29]$. Timing is an essential element in transition, and the transfer should be timed flexibly and decided jointly with young people [3], but in our sample, only $40 \%$ felt that they had been involved, and about half thought the timing had been right. Transfer usually took place at 17 or 18 years of age, close to what is sometimes reported as "the ideal age" [39], but unlike in another study [29], age at transfer did not influence experiences or satisfaction.

Our results indicate that the conditions for successful transition preparation and planning were not met $[3,10]$. About $64 \%$ of respondents felt they had been ready to transfer, a lower percentage than reported before [19,40]. Preparing adolescents for future independent roles and assessing transition readiness deserve more attention $[16,34,35]$. For example, only $23.5 \%$ had met their adult providers in advance. Transition clinics offering this opportunity seem successful in increasing faith in their new providers $[18,40]$, and there is some evidence for their effectiveness $[8,9]$.

\section{Strengths and limitations}

Strength of the study was the longitudinal design, enabling to determine what happened to a wide sample of YA after 6 years of follow-up. Although the sample was fairly large, survey nonresponse was high (48.2\%) especially among males and YA of non-Dutch ethnicity. This group may have included those who dropped out of care or distrusted their new doctor. Another limitation was that we only had healthcare utilization data from those that transferred within the same hospital. Future studies could adopt a more rigorous design involving all YA transferred from a clinic. Finally, we examined a large heterogeneous sample because adolescents with any kind of chronic condition are facing the same challenges during their transition to adulthood [1]. This generic approach limited the inclusion of disease-specific outcomes including disease severity and the opportunity to research the effects of interventions employed by specialty clinics. However, transition issues are often not disease specific, and the use of general tools like the TES to measure transition experiences might allow for transition research in less common diseases and comparisons between disease groups [35].

The newly developed OYOF-TES showed good reliability and internal consistency and met most of the COSMIN criteria [20]. The measurement covers all four themes 
distilled from a qualitative review into adolescents' experiences with transition [14]. The OYOF-TES is an improvement over existing measures [16], although further validation in other populations is needed. Also, to improve the specificity and usability of the measurement for quality improvement, it would be advisable to compare the OYOF-TES with the Health Care Transition Feedback Survey for Youth to determine whether the Six Core Elements of Transition are adequately covered (www.gottransition.org) [41].

Our research suggests that while adolescents should be better prepared for and involved in transition, it is health-care providers' first priority to build bridges between pediatric and adult-oriented care. Responsibility for a safe and smooth transition extends beyond pediatrics: transitional care should therefore not be restricted to the child-oriented services. Gaining trust and investing in new personal relations is the way forward for all parties involved: transition is about responding and bonding.

\section{Acknowledgments}

We thank the other members of the On Your Own Feet Research Group (Jos Latour, Ph.D. and Linda van der Knaap, M.A.N.P. from Erasmus University Medical Center Rotterdam; Susan Jedeloo, Ph.D., Heleen van der Stege, Ph.D., and Sander Hilberink, Ph.D. from Rotterdam University of Applied Sciences) for their contribution to the design, execution, and reporting of the study. The following students are thanked for their contribution: Patrick Polak, B.Sc. helped reviewing the existing transfer experiences measurements, while Kimberly Onderdijk and Esmee Kuppen (both Bachelor of speech language therapist) helped pretesting the questionnaire. Finally, we thank Prof. Bert van der Heijden, then head of the Department of Pediatrics of Erasmus Medical Center, for providing us with the original idea to perform this study.

This work was presented at the 10th World Congress on Adolescent Health in Istanbul, Turkey (June 2013) and at the 18th European Congress of International Association for Adolescent Health in Paris, France (June 2014).

\section{Funding Sources}

The On Your Own Feet program (2004-2008) was funded by ZonMw, The Netherlands Organization for Health Research and Development (grant 32560005) and the Dutch Charity Foundation Kinderpostzegels (grant 23674/1/4). The followup study was part of the SPIL: Self-Management and Participation Innovation Lab, supported by SIA-RAAK, the Foundation Innovation Alliance with funding from the Dutch Ministry of Education, Culture and Science (OCW) (PRO-02-025). The funding sources had no role in the design and conduct of the study; collection, management, analysis, and interpretation of the data; preparation, review, or approval of the manuscript; and decision to submit the manuscript for publication.

\section{Supplementary Data}

\section{REFERENCES}

[1] S.M. Sawyer, S. Drew, M.S. Yeo, et al.Adolescents with a chronic condition: Challenges living, challenges treating Lancet, 369 (2007), pp. 1481-1489 
Staa, A. van, Sattoe, J.N.T. Young adults' experiences and satisfaction with the transfer of careJournal of Adolescent Health: 2014, 55(6), 796-803

[2] R.W. Blum, D. Garell, C.H. Hodgman, et al.Transition from child-centered to adult healthcare systems for adolescents with chronic conditions. A position paper of the Society for Adolescent Medicine

J Adolesc Health, 14 (1993), pp. 570-576

[3] American Academy of Pediatrics, American Academy of Family physicians, American College of Physicians, et al.Supporting the health care transition from adolescence to adulthood in the medical home

Pediatrics, 128 (2011), pp. 182-200

[4] P. Rapley, P.M. DavidsonEnough of the problem: A review of time for health care transition solutions for young adults with a chronic illness

J Clin Nurs, 19 (2010), pp. 313-323

[5] S.E. McLaughlin, M. Diener-West, A. Indurkhya, et al.Improving transition from pediatric to adult cystic fibrosis care: Lessons from a national survey of current practices

Pediatrics, 121 (2008), pp. e1160-e1166

[6] C. Grant, J. PanA comparison of five transition programmes for youth with chronic illness in Canada

Child Care Health Dev, 37 (2011), pp. 815-820

[7] M.A. McManus, L.R. Pollack, W.C. Cooley, et al.Current status of transition preparation among youth with special needs in the United States

Pediatrics, 131 (2013), pp. 1090-1097

[8] S.R. Bloom, K. Kuhlthau, J. Van Cleave, et al.Health care transition for youth with special health care needs

J Adolesc Health, 51 (2012), pp. 213-219

[9] R. Crowley, I. Wolfe, K. Lock, et al.Improving the transition between paediatric and adult healthcare: A systematic review

Arch Dis Child, 96 (2011), pp. 548-553

[10]T. Lugasi, M. Achille, M. StevensonPatients' perspective on factors that facilitate transition from child-centered to adult-centered health care: A theory integrated metasummary of quantitative and qualitative studies

J Adolesc Health, 48 (2011), pp. 429-440

[11] R. Watson, J.R. Parr, C. Joyce, et al.Models of transitional care for young people with complex health needs: A scoping review

Child Care Health Dev, 37 (2011), pp. 780-791

[12] C.L. Betz, M.L. Lobo, W.M. Nehring, et al.Voices not heard: A systematic review of adolescents' and emerging adults' perspectives of health care transition

Nurs Outlook, 61 (2013), pp. 311-336

[13] A.L. van Staa, S. Jedeloo, J. van Meeteren, et al.Crossing the transition chasm: Experiences and recommendations for improving transitional care of young adults, parents and providers

Child Care Health Dev, 37 (2011), pp. 821-832

[14] L. Fegran, E.O. Hall, L. Uhrenfeldt, et al.Adolescents' and young adults' transition experiences when transferring from paediatric to adult care: A qualitative metasynthesis

Int J Nurs Stud, 51 (2014), pp. 123-135

[15] C.L. Betz, K. SmithMeasuring health care transition planning outcomes: Challenges and issues

Int J Child Adolesc Health, 3 (2010), pp. 463-472

[16] J. Stinson, S.A. Kohut, L. Spiegel, et al.A systematic review of transition readiness and transfer satisfaction measures for adolescents with chronic illness

Int J Adolesc Med Health, 26 (2014), pp. 159-174

[17] F.P. Busse, P. Hiermann, A. Galler, et al.Evaluation of patients' opinion and metabolic control after transfer of young adults with type 1 diabetes from a pediatric diabetes clinic to adult care

Horm Res, 67 (2007), pp. 132-138

[18] R.D. Latzman, S. Majumdar, C. Bigelow, et al.Transitioning to adult care among adolescents with sickle cell disease: A transitioning clinic based on patient and caregiver concerns and needs

Int J Child Adolesc Health, 3 (2010), pp. 537-545 
Staa, A. van, Sattoe, J.N.T. Young adults' experiences and satisfaction with the transfer of careJournal of Adolescent Health: 2014, 55(6), 796-803

[19] K.C. Garvey, H.A. Wolpert, L.M. Laffel, et al.Health care transition in young adults with type 1 diabetes: Barriers to timely establishment of adult diabetes care

Endocr Pract, 19 (2013), pp. 946-952

[20] C.B. Terwee, L.B. Mokkink, D.L. Knol, et al.Rating the methodological quality in systematic reviews of studies on measurement properties: A scoring system for the COSMIN checklist

Qual Life Res, 21 (2012), pp. 651-657

[21] K.L. Shaw, T.R. Southwood, J.E. McDonaghDevelopment and preliminary validation of the 'Mind the Gap' scale to assess satisfaction with transitional health care among adolescents with juvenile idiopathic arthritis

Child Care Health Dev, 33 (2007), pp. 380-388

[22] A.F. Colver, H. Merrick, M. Deverill, et al.Study protocol: Longitudinal study of the transition of young people with complex health needs from child to adult health services BMC Public Health, 13 (2013), p. 675

[23] L.K. Tuchman, G.B. Slap, M.T. BrittoTransition to adult care: Experiences and expectations of adolescents with a chronic illness

Child Care Health Dev, 34 (2008), pp. 557-563

[24] A.L. van Staa, H.A. van der Stege, S. Jedeloo, et al.Readiness to transfer to adult care of adolescents with chronic conditions: Exploration of associated factors

J Adolesc Health, 48 (2011), pp. 295-302

[25] C. Jenkinson, A. Coulter, S. Bruster, et al.Patients' experiences and satisfaction with health care: Results of a questionnaire study of specific aspects of care

Qual Saf Health Care, 11 (2002), pp. 335-339

[26] D.M. Delnoij, G. ten Asbroek, O.A. Arah, et al.Made in the USA: The import of American Consumer Assessment of Health Plan Surveys (CAHPS) into the Dutch social insurance system

Eur J Public Health, 16 (2006), pp. 652-659

[27] M.C. Simeoni, S. Schmidt, H. Muehlan, et al.Field testing of a European quality of life instrument for children and adolescents with chronic conditions: The 37-item DISABKIDS Chronic Generic Module

Qual Life Res, 16 (2007), pp. 881-893

[28] M. McPherson, L. Thaniel, C.P. MinnitiTransition of patients with sickle cell disease from pediatric to adult care: Assessing patient readiness

Pediatr Blood Cancer, 52 (2009), pp. 838-841

[29] G. Steinkamp, G. Ullrich, C. Muller, et al.Transition of adult patients with cystic fibrosis from paediatric to adult care-the patients' perspective before and after start-up of an adult clinic

Eur J Med Res, 6 (2001), pp. 85-92

[30] C. Rutishauser, S.M. Sawyer, A.E. AmbresinTransition of young people with chronic conditions: A cross-sectional study of patient perceptions before and after transfer from pediatric to adult health care

Eur J Pediatr (2014), 10.1007/s00431-014-2291-9

[31] M.T. Britto, R.F. DeVellis, R.W. Hornung, et al.Health care preferences and priorities of adolescents with chronic illnesses

Pediatrics, 114 (2004), pp. 1272-1280

[32] N.G. Peter, C.M. Forke, K.R. Ginsburg, et al.Transition from pediatric to adult care: Internists' perspectives

Pediatrics, 123 (2009), pp. 417-423

[33] J.C. Suris, C. Akre, C. RutishauserHow adult specialists deal with the principles of a successful transition

J Adolesc Health, 45 (2009), pp. 551-555

[34] G.S. Sawicki, K. Lukens-Bull, X. Yin, et al.Measuring the transition readiness of youth with special healthcare needs: Validation of the TRAQ-Transition readiness assessment questionnaire

J Pediatr Psychol, 36 (2011), pp. 160-171

[35] L.F. Zhang, J.S. Ho, S.E. KennedyA systematic review of the psychometric properties of transition readiness assessment tools in adolescents with chronic disease

BMC Pediatr, 14 (2014), p. 4 
Staa, A. van, Sattoe, J.N.T. Young adults' experiences and satisfaction with the transfer of care. Journal of Adolescent Health: 2014, 55(6), 796-803

[36] H. Gleeson, S. McCartney, V. Lidstone'Everybody's business': Transition and the role of adult physicians

Clin Med, 12 (2012), pp. 561-566

[37] A. Kennedy, S. SawyerTransition from pediatric to adult services: Are we getting it right? Curr Opin Pediatr, 20 (2008), pp. 403-409

[38] J. Downing, H.K. Gleeson, P.E. Clayton, et al.Transition in endocrinology: The challenge of maintaining continuity

Clin Endocrinol (Oxf), 78 (2013), pp. 29-35

[39] A. Godbout, I. Tejedor, S. Malivoir, et al.Transition from pediatric to adult healthcare: Assessment of specific needs of patients with chronic endocrine conditions Horm Res Paediatr, 78 (2012), pp. 247-255

[40] A. Dabadie, F. Troadec, D. Heresbach, et al.Transition of patients with inflammatory bowel disease from pediatric to adult care

Gastroenterol Clin Biol, 32 (2008), pp. 451-459

[41] Web site: Got Transition? Center for Health Care Transition Improvement. The Six Core Elements of Health Care Transition. Available at: http://www.gottransition.org/6-coreelements. Accessed April 11, 2014. 
Table 1

Description of the study sample ( $\mathrm{n}=315$, unless otherwise indicated)

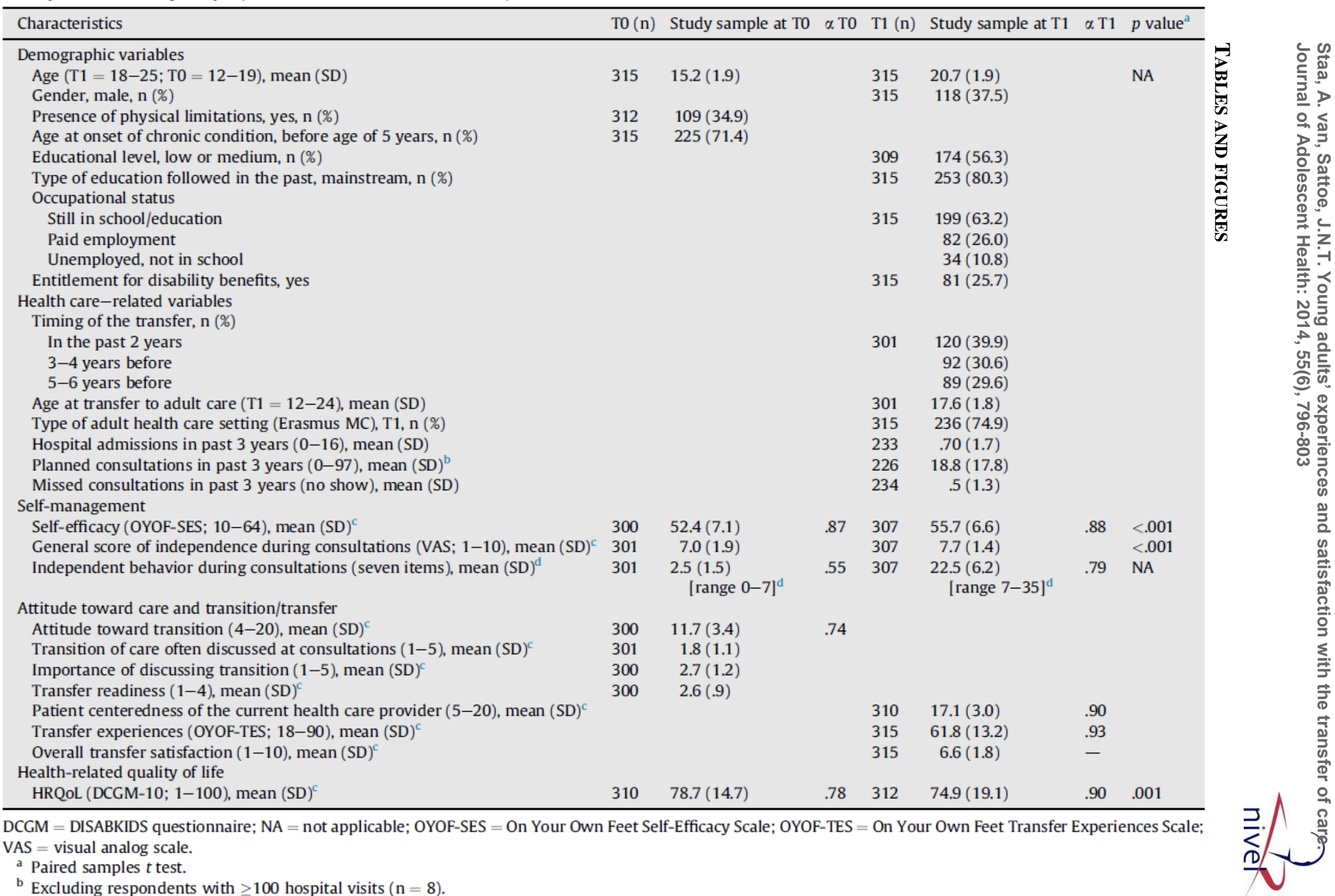

b Excluding respondents with $\geq 100$ hospital visits $(n=8)$.

c Theoretical range.

${ }^{\mathrm{d}}$ Independent behavior during consultations was self-reported, at T0 with a dichotomous scale $(\alpha=.55)$; whereas, at T1 a five-point Likert scale was used ( $\left.\alpha=.79\right)$. 
Staa, A. van, Sattoe, J.N.T. Young adults' experiences and satisfaction with the transfer of caren Journal of Adolescent Health: 2014, 55(6), 796-803

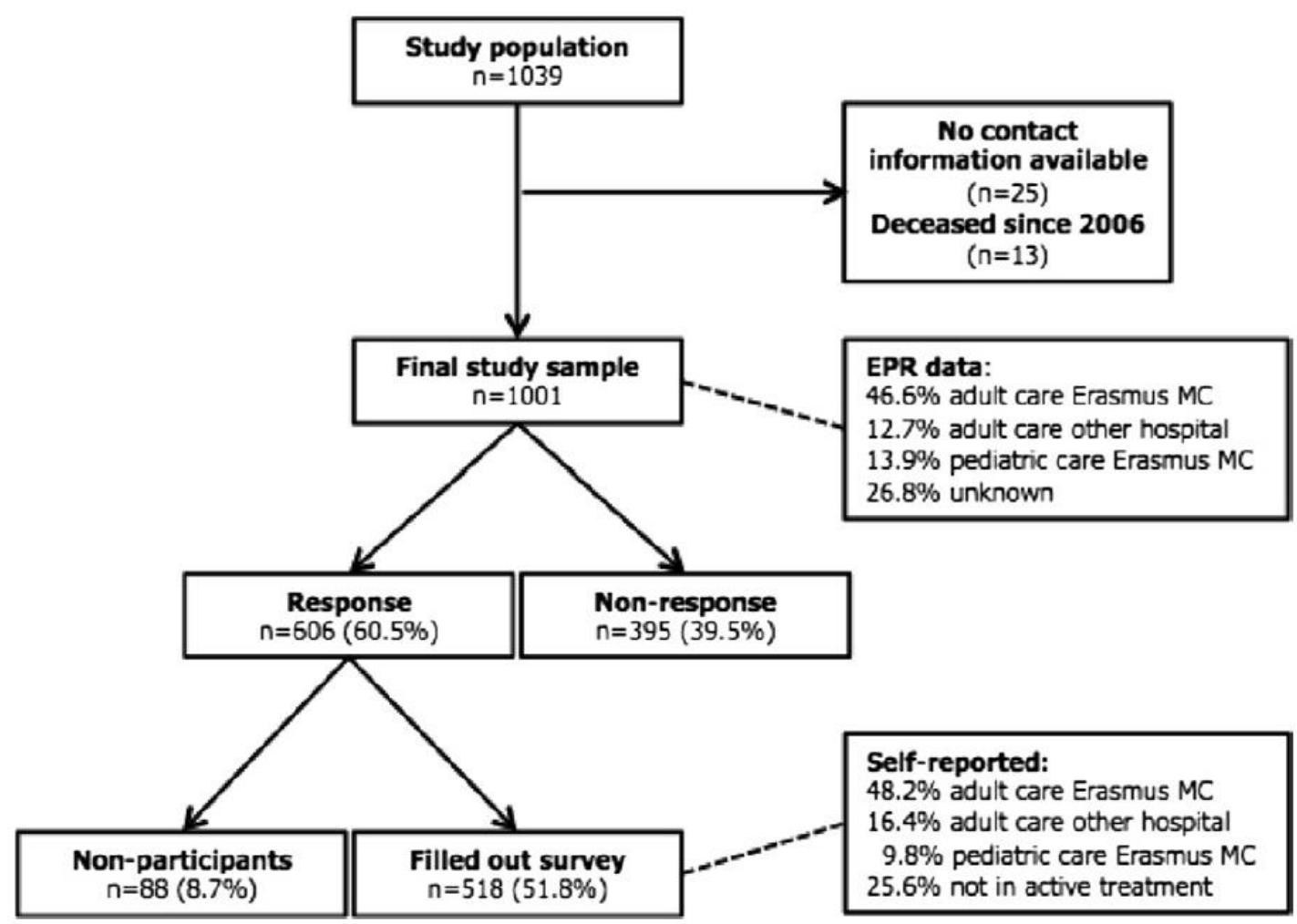

Figure 2. Distribution of transfer satisfaction $(n=315)$.

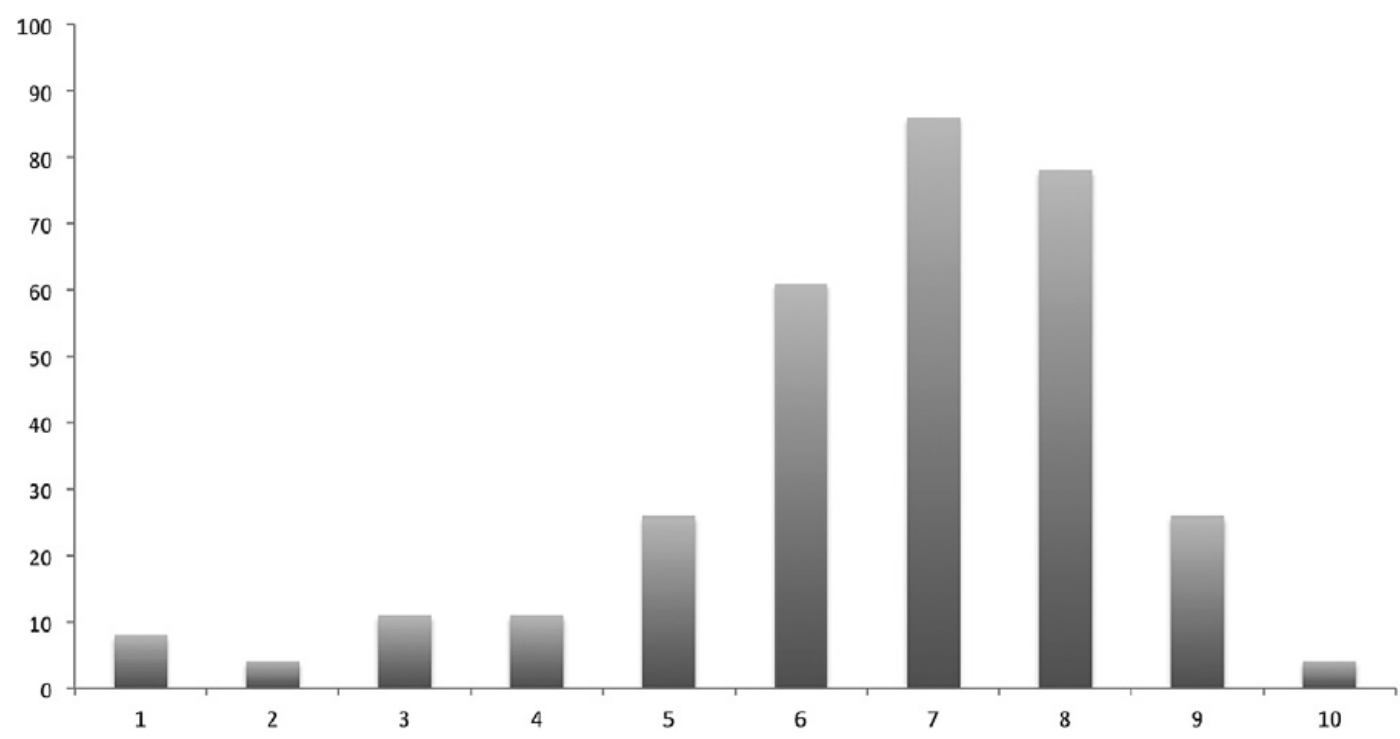


Staa, A. van, Sattoe, J.N.T. Young adults' experiences and satisfaction with the transfer of caren Journal of Adolescent Health: 2014, 55(6), 796-803

\section{Table 2}

Bivariate correlations of variables with the total OYOF-TES score and transfer satisfaction (T0 and T1; Pearson or Spearman correlation coefficient $r / \rho$ )

\begin{tabular}{|c|c|c|c|c|c|}
\hline & $\mathrm{n}$ & $\begin{array}{l}\text { OYOF-TES } \\
\text { total }\end{array}$ & $\begin{array}{l}p \\
\text { value }\end{array}$ & $\begin{array}{l}\text { Overall } \\
\text { transfer } \\
\text { satisfaction }\end{array}$ & $\begin{array}{l}p \\
\text { value }\end{array}$ \\
\hline \multicolumn{6}{|l|}{ T0 } \\
\hline $\begin{array}{l}\text { Presence of physical } \\
\text { limitations }\end{array}$ & 312 & -.10 & .09 & -.06 & .26 \\
\hline $\begin{array}{l}\text { Age at onset of chronic } \\
\text { condition }\end{array}$ & 315 & -.06 & .27 & -.04 & .54 \\
\hline Self-efficacy (OYOF-SES), T0 & 300 & .15 & .01 & .11 & .05 \\
\hline $\begin{array}{l}\text { General score of } \\
\text { independence during } \\
\text { consultations (VAS), T0 }\end{array}$ & 301 & .07 & .25 & .01 & .93 \\
\hline $\begin{array}{l}\text { Independent behaviors } \\
\text { during the last } \\
\text { consultation, T0 }\end{array}$ & 301 & -.04 & .45 & -.06 & .30 \\
\hline Attitude toward transition, T0 & 300 & .26 & $<.001$ & .16 & .01 \\
\hline $\begin{array}{l}\text { Transition of care often } \\
\text { discussed at } \\
\text { consultations, T0 }\end{array}$ & 301 & -.02 & .75 & .00 & .97 \\
\hline $\begin{array}{l}\text { Importance of discussing } \\
\text { transition, T0 }\end{array}$ & 300 & .12 & .04 & .15 & .01 \\
\hline Transfer readiness, T0 & 300 & .08 & .18 & .04 & .51 \\
\hline HRQOL (DCGM-10), TO & 310 & .13 & .02 & .09 & .10 \\
\hline \multicolumn{6}{|l|}{$\mathrm{T} 1$} \\
\hline Age & 315 & -.02 & .70 & -.04 & .53 \\
\hline Gender & 315 & .27 & $<.001$ & .18 & .002 \\
\hline Educational level & 309 & .00 & .98 & .03 & .56 \\
\hline $\begin{array}{l}\text { Type of education followed } \\
\text { in the past }\end{array}$ & 315 & -.06 & .31 & -.07 & .23 \\
\hline $\begin{array}{l}\text { Entitlement for disability } \\
\text { benefits }\end{array}$ & 315 & -.07 & .22 & -.07 & .24 \\
\hline Timing of transfer & 301 & -.04 & .53 & -.10 & .09 \\
\hline Age at transfer & 301 & -.79 & .17 & -.01 & .87 \\
\hline $\begin{array}{l}\text { Type of adult health care } \\
\text { setting (Erasmus MC), T1 }\end{array}$ & 315 & .08 & .18 & .14 & .01 \\
\hline $\begin{array}{l}\text { Self-efficacy change } \\
\quad(\text { OYOF-SES), T1 - T0 }(\Delta)\end{array}$ & 294 & .17 & .004 & .09 & .122 \\
\hline $\begin{array}{l}\text { General score of } \\
\text { independence during } \\
\text { consultations (VAS), T1 }\end{array}$ & 307 & .18 & .001 & .16 & .005 \\
\hline $\begin{array}{l}\text { Independent behaviors } \\
\text { during the last } \\
\text { consultation, T1 }\end{array}$ & 307 & .15 & .009 & .10 & .07 \\
\hline $\begin{array}{l}\text { Patient centeredness of the } \\
\text { current health care } \\
\text { provider, T1 }\end{array}$ & 310 & .40 & $<.001$ & .39 & $<.001$ \\
\hline $\begin{array}{l}\text { HRQoL change (DCGM-10), } \\
\quad \text { T1 - TO }(\Delta)\end{array}$ & 308 & .17 & $<.003$ & .16 & .006 \\
\hline
\end{tabular}

DCGM = DISABKIDS questionnaire; HRQoL = Health-related quality of life; OYOF-SES = On Your Own Feet Self-Efficacy Scale; OYOF-TES = On Your Own Feet Transfer Experiences Scale; VAS = visual analog scale. 
Table 3

Multivariate linear regression analyses of associations with transfer experiences (OYOF-TES) and transfer satisfaction (standardized betas $\beta ; \mathrm{n}=293$ )

\begin{tabular}{|c|c|c|c|c|c|c|}
\hline & \multicolumn{2}{|l|}{ Step 1} & \multicolumn{2}{|l|}{ Step 2} & \multicolumn{2}{|l|}{ Step 3} \\
\hline & $\beta$ & $p$ value & $\beta$ & $p$ value & $\beta$ & $p$ value \\
\hline \multicolumn{7}{|l|}{ OYOF-TES } \\
\hline Gender (male) & .28 & $<.001$ & .23 & $<.001$ & .17 & .001 \\
\hline Self-efficacy (OYOF-SES), T0 & & & .09 & .13 & .13 & .12 \\
\hline Attitude toward transition, T0 & & & .16 & .006 & .15 & .005 \\
\hline Importance of discussing transition, $\mathrm{TO}$ & & & .05 & .34 & .05 & .36 \\
\hline HRQoL (DCGM-10), T0 & & & .09 & .13 & .08 & .18 \\
\hline Self-efficacy change T1 - TO $(\Delta)$ & & & & & .16 & .05 \\
\hline HRQoL change T1 - T0 $(\Delta)$ & & & & & .10 & .08 \\
\hline Type of adult health care setting (Erasmus MC), T1 & & & & & .08 & .13 \\
\hline General score of independence during consultations (VAS), T1 & & & & & .01 & .85 \\
\hline Independent behaviors during the last consultation, $\mathrm{T} 1$ & & & & & .04 & .53 \\
\hline Patient centeredness of the current health care provider, $\mathrm{T} 1$ & & & & & .29 & $<.001$ \\
\hline Explained variance final model & $R^{2}=.08$ & $<.001$ & $R^{2}=.14$ & $<.001$ & $R^{2}=.30$ & $<.001$ \\
\hline$F$ value (df) & $25.37(1,291)$ & & $9.16(5,287)$ & & $10.78(11,281)$ & \\
\hline \multicolumn{7}{|l|}{ Transfer satisfaction } \\
\hline Gender (male) & .21 & $<.001$ & .18 & .003 & .12 & .03 \\
\hline Self-efficacy (OYOF-SES), T0 & & & .08 & .20 & .04 & .66 \\
\hline Attitude toward transition, To & & & .07 & .25 & .06 & .26 \\
\hline Importance of discussing transition, T0 & & & .11 & .06 & .11 & .04 \\
\hline HRQOL (DCGM-10), TO & & & .07 & .23 & .08 & .19 \\
\hline Self-efficacy change T1 - TO $(\Delta)$ & & & & & .01 & .92 \\
\hline HRQoL change T1 - T0 $(\Delta)$ & & & & & .10 & .10 \\
\hline Type of adult health care setting (Erasmus MC), T1 & & & & & .28 & $<.001$ \\
\hline General score of independence during consultations (VAS), T1 & & & & & .03 & .66 \\
\hline Independent behaviors during the last consultation, $\mathrm{T} 1$ & & & & & .03 & .69 \\
\hline Patient centeredness of the current health care provider, T1 & & & & & .16 & .004 \\
\hline Explained variance final model & $R^{2}=.05$ & $<.001$ & $R^{2}=.08$ & $<.001$ & $R^{2}=.21$ & $<.001$ \\
\hline$F$ value (df) & $14.00(1,291)$ & & $5.06(5,87)$ & & $6.92(11,281)$ & \\
\hline
\end{tabular}

DCGM = DISABKIDS questionnaire; HRQoL = Health-related quality of life; OYOF-SES = On Your Own Feet Self-Efficacy Scale; OYOF-TES = On Your Own Feet Transfe Experiences Scale; VAS = visual analog scale. 

satisfaction (VAS) $(n=315)$

\begin{tabular}{|c|c|c|c|c|}
\hline & $\begin{array}{l}\text { Item } \\
\text { mean }(S D)^{a}\end{array}$ & $\begin{array}{l}\text { Agree } \\
(\%)^{b}\end{array}$ & $\begin{array}{l}\text { Factor } \\
\text { loading }\end{array}$ & $\begin{array}{l}\text { Correlation } \\
\text { with transfer } \\
\text { satisfaction }^{c}\end{array}$ \\
\hline \multicolumn{4}{|l|}{$\begin{array}{l}\text { Subscale A - Alignment between pediatric and adult care } \\
(\text { mean = } 37.47(8.64) ; \text { Cronbach's alpha }=.91)\end{array}$} & .73 \\
\hline $\begin{array}{l}\text { I can manage well on my own during hospital } \\
\text { consultations, also without my parents }\end{array}$ & $4.00(0.96)$ & 78.7 & .35 & .25 \\
\hline I have confidence in my adult health care providers & $3.98(0.92)$ & 80.9 & .78 & .56 \\
\hline $\begin{array}{l}\text { I am happy with the care I receive in the adult care } \\
\text { setting }\end{array}$ & $3.79(0.95)$ & 73.6 & .82 & .60 \\
\hline $\begin{array}{l}\text { My new care provider was well informed about me and } \\
\text { my condition }\end{array}$ & $3.67(1.10)$ & 67.0 & .84 & .62 \\
\hline I was taken care of very well in the adult care setting & $3.64(1.04)$ & 65.4 & .72 & .64 \\
\hline $\begin{array}{l}\text { Treatment recommendations in the adult care setting are } \\
\text { similar to those I used to receive in pediatric care }\end{array}$ & $3.36(1.17)$ & 56.2 & .85 & .56 \\
\hline $\begin{array}{l}\text { There was good collaboration between pediatric and } \\
\text { adult care }\end{array}$ & $3.35(1.09)$ & 51.4 & .78 & .64 \\
\hline $\begin{array}{l}\text { The way of working and dealings with patients in adult } \\
\text { care are similar to what I was used to in pediatric care }\end{array}$ & $3.20(1.17)$ & 47.9 & .85 & .56 \\
\hline $\begin{array}{l}\text { When I first met my adult care provider, I knew exactly } \\
\text { what was expected of me and what I could expect from } \\
\text { him / her }\end{array}$ & $3.05(1.14)$ & 38.1 & .55 & .51 \\
\hline $\begin{array}{l}\text { I don't really experience many differences between } \\
\text { pediatric and adult care }\end{array}$ & $3.03(1.22)$ & 41.3 & .75 & .51 \\
\hline $\begin{array}{l}\text { Before the transfer I had already met my new health } \\
\text { care providers }\end{array}$ & $2.40(1.25)$ & 23.5 & .45 & .33 \\
\hline \multicolumn{4}{|l|}{$\begin{array}{l}\text { Subscale B - Preparation for transfer } \\
\text { mean = } 24.36 \text { (5.98); Cronbach's alpha }=.89)\end{array}$} & .62 \\
\hline $\begin{array}{l}\text { The transfer to adult care was announced timely and did } \\
\text { not come as a surprise }\end{array}$ & $3.91(1.05)$ & 77.2 & .80 & .46 \\
\hline My parents were ready to transfer to adult care & $3.80(0.99)$ & 69.5 & .77 & .42 \\
\hline I was ready to transfer to adult care & $3.70(1.12)$ & 63.8 & .85 & .46 \\
\hline The timing of the transfer was just about right & $3.46(1.03)$ & 51.8 & .80 & .53 \\
\hline I was well prepared for the transfer to adult care & $3.30(1.09)$ & 49.2 & .67 & .58 \\
\hline $\begin{array}{l}\text { I received enough information about the transfer to adult } \\
\text { care }\end{array}$ & $3.17(1.12)$ & 43.8 & .59 & .52 \\
\hline I had a say in the timing of the transfer & $3.02(1.25)$ & 39.7 & .76 & .40 \\
\hline
\end{tabular}

a 4-point Likert scale ( $1=$ no, definitely not; $2=$ no, probably not; $3=y e s$, probably; $4=y e s$ certainly).

b Only those young adults who scored 'agree' and 'strongly agree'.

${ }^{c}$ Pearson's correlation coefficient $r$ (all $P<.001$ ) 